\title{
ЗНАЧЕНИЕ РЕКОМЕНДАЦИИ REC (99) 22 ПО ВОПРОСАМ ПЕРЕНАСЕЛЕННОСТИ (ПЕРЕПОЛНЕННОСТИ) МЕСТ ЗАКЛЮЧЕНИЯ И УВЕЛИЧЕНИЯ ЧИСЛЕННОСТИ ЗАКЛЮЧЕННЫХ
}

\author{
Миджоска E.
}

Аннотация: Проведен детальный сравнительно-правовой анализ международных рекомендаций на пенитенцииарные системы различных государств, обеспечивающих достижение целей наказания как важного элемента политики борьбы с преступностью. Рассмотрены различные конструкиии законодательных норм ряда государств, отражающих современные решения и рекомендации международных документов, касаюшихся вопросов перенаселенности тюрем, в связи со стремительным ростом числа заключенных. Автором проанализирована структура и основные принципы Рекомендации Rec (99) 22, а также представлено собственное мнение относительно ее научной обоснованности на фоне многочисленных дискуссий по имеющимся проблемам ее применения государствами-членами СЕ. Приведен сравнительный обзор и статистика перенаселенности (переполненности) учреждений тюремного типа, на примере ряда государств, таких как Франция, Бельгия и Россия, а также сравнительный анализ международных документов, посвященных указанной проблеме. Методология: диалектика, абстрагирование, анализ, синтез, дедукиия, сравнительно-правовой, формально-юридический метод, метод межотраслевых юридических исследований. Выводы. На современном этапе развития мировой уголовно-правовой политики переполненность тюрем и рост числа заключенных это серьезная проблема для пенитенциарных учреждений и системы уголовного правосудия в иелом с точки зрения соблюдения прав человека и норм эффективного управления. Необходима разработка и реализация эффективных мер по борьбе с переполненностью тюрем и сокращением численности заключенных, которые должны представлять собой последовательную и рациональную политику борьбы с преступностью, направленную на предотвращение преступлений и преступного 
поведения, эффективное правоприменение, обеспечение защчиты общества и безопасности государства от преступных посягательств.Научная и практическая значимость. Исследования и анализ последних статистических данных в отнотении заключенных, показывают, что перенаселенность и высокий уровень рецидива являются насущными проблемами современных пенитенциарных систем многих стран. Ключевые слова: Заключенный, содержание под стражей, личение свободы, пенитенциарные учреждения, пенитенциарные правила, пенитенциарная система, преступность, наказание, права человека, борьба с преступностью.

Благополучие и уважение основных прав человека и человеческого достоинства являются фундаментальными ценностями, общими для всех стран и общество стремится поддерживать эти ценности на равноправной основе.

Если основными принципами организации общества являются: верховенство закона, легитимность и равенство людей, демократия, гуманность и уважение достоинства человека, то тогда возникает необходимость решения двух задач: во-первых, какую следует строить пенитенциарную систему, направленную на человечное и уважительное отношение к личности осужденных или регулирующую репрессивный подход к исполнению уголовных наказаний и, во-вторых, создание пенитенциарной системы в порядке и на условиях, обеспечивающих достижение цели наказания как важного элемента политики борьбы с преступностью.[1]

Анализ международного права и иных нормативных документов служит в качестве модели конструирования конкретных законодательных норм, отражающих современные решения и рекомендации международных документов, в первую очередь документов $\mathrm{OOH,} \mathrm{Совета} \mathrm{Европы} \mathrm{и} \mathrm{Европейского}$
Союза, обеспечивающих все надлежащие государственные законодательные меры, касающиеся вопросов перенаселенности тюрем и стремительного роста числа заключенных. Следует отметить, что проводимые ранее исследования воспринимались как усилия, предпринимаемые для подчеркивания необходимости обратить особое внимание на вопросы эффективного управления заключенными и общий подход к решению проблемы роста преступности.

Стоящий особняком и имеющий важное практическое значение, является нормативный документ, известный как Европейские пенитенциарные правила, принятый Советом Европы в 1987 году. Принятие этого документа доказывает стремление Совета Европы последовательно реализовывать рекомендации и руководящие принципы Организации Объединенных Наций, проявляя полное уважение к концепции защиты гарантированных прав и свобод, изложенных в Европейской конвенции по правам человека. Европейские пенитенциарные правила усовершенствовались с принятием Рекомендации Rec (2006) 2 Комитета Министров государств-членов Совета Европы по Европейским тюремным 
правилам, чем был задан тон всему тексту Правил.

Концепция прав и свобод как высшая цивилизационная ценность современного общества не сохраняет данный человеку от рождения свой первозданный вид раз и навсегда, но будучи динамично развивающимся процессом, добавляет к имеющимся новую порцию прав и свобод, новые ценности и новые гарантии их реализации.[2] Все это подтверждается принятием поправок в Европейские пенитенциарные правила 2006 года.

Рекомендацией Rec (2006) 2 предусмотрено, что помимо положений Европейской конвенции по правам человека, рассмотренных прецедентов Европейского суда по правам человека (ЕСПЧ) и работы Европейского комитета по предупреждению пыток, бесчеловечного и унижающего достоинство обращения или наказания (ЕКПП), действуют, в частности, и стандарты, принятые в итоговых докладах указанных организаций.

\section{1. Общие замечания}

Преступность неуклонно растет, и как никогда раньше создает угрозу функционированию правовой системы. В некоторых странах проблема приобрела такие размеры, что само понятие преступности становится образом жизни, а с использованием новых, более масштабных достижений в области науки, искусства и техники - и мощным инструментом для осуществления преступных деяний. Совет Европы идет в ногу с новыми идеями и соответственно дает рекомендации, которые частично или полностью заменяют устаревшие ссылки. С другой стороны, существуют и очень актуальные до сих пор решения сорокалетней давности, значительно влияющие на современный правовой процесс. Но некоторые решения устарели и, в связи с введением новых европейских стандартов и современных наработок в криминологической науке о наказании, исключены из правовой системы.

В отношении регулирования вопросов, касающихся прав лиц, лишенных свободы и условий их содержания в заключении, действуют старые решения, которые полностью или частично покрывают эти вопросы и поэтому принятия новых решений не требуется. 30 сентября 1999 года на 681-м заседании Комитета Министров министры - депутаты приняли Рекомендацию R (99) 22 о перенаселенности (переполненности) мест заключения и об увеличении численности заключенных (далее по тексту: Рекомендация № R (99) 22).

Вопросы о мерах наказания, альтернативных лишению свободы, об отсрочке исполнения наказания и его альтернативных видах, предусмотренные Решениями (76) 10 и (65) 1 , в значительной степени устарели в сравнении с Рекомендациями R (99) 22.

Следующее Решение (66) 25 касается краткосрочного задержания молодых правонарушителей до 21 лет. Это решение не отменено, но также фактически не действует в связи с существующими новыми европейскими правилами, предусматривающими регулирование правовых норм в отношении несовершеннолетних правонарушителей, применения к ним санкций, 
связанных с лишением свободы, или иных мер наказания, но по этому вопросу ожидается принятие резолюции Комитета Министров.

Наконец, нельзя не упомянуть Постановление (73) 17 о краткосрочном задержании взрослых правонарушителей, содержание текста которого подверглось наибольшему изменению. Рекомендация по его применению также отсутствует.

R (99) 22, как результат новой уголовно-правовой политики, во главу угла своего объекта исследования ставит научные достижения, ежедневно пополняемые новыми идеями, знаниями, новыми видами технологий и оборудования, новыми методами и т.д.

Таким образом, Рекомендация о перенаселенности (переполненности) мест заключения и увеличении численности заключенных, это единственная рекомендация, которая все еще применяется, несмотря на многочисленные вопросы, дебаты и социальные последствия, которые она вызывает. Ответом на вопрос, можно ли считать эту рекомендацию научно обоснованной и нужны ли многочисленные дискуссии по имеющейся проблеме, послужит дальнейшее краткое пояснение ее структурной и смысловой части.

\section{2. Структура и смысл Рекомендации № R (99) 22}

Каждое правительство государства - члена Совета Европы должно принять все необходимые меры для реализации принципов, изложенных в поправках к Рекомендации № R (99) 22 , включающей пять разделов.
В Первом разделе под названием «Основные принципы» подчеркивается, что содержание в заключении должно рассматриваться в качестве крайней меры наказания, то есть учитывая тяжесть содеянного, отсутствует возможность применения иной санкции (принцип 1).

Далее, Договаривающиеся Стороны настоящей рекомендацией устанавливают необходимость реализации положения о дифференцированном подходе в отношении санкций и иных мер общественного воздействия с возможностью как можно более широкого поощрения к этому судей и прокуроров (принципы 2,3).

Большое значение имеет принцип 4 по вопросу о возможности декриминализации отдельных видов преступлений или их переквалификации при вынесении приговоров, связанных с лишением свободы.

Второй раздел под названием «Борьба с перенаселенностью учреждений тюремного типа» содержит принцип, являющийся предметом рассмотрения этой статьи. Таковым является принцип 9, суть которого не в ограничении наказания только лишением свободы, а с целью способствовать исправлению и реабилитации заключенных, поддержанию связей со своими семьями и другими общественными отношениями и уменьшения напряженности в пенитенциарных учреждениях, в возможности использования в период лишения свободы и других конкретных механизмов, сочетаемых с этим наказанием, таких как ограниченная свобода, открытый режим содержания или выход за пре- 
делы городской тюрьмы. Конечно, этот принцип действует в отношении осужденных на короткие сроки лишения свободы, совершивших менее тяжкие преступления и не считающихся опасными для общества, но, и в такой форме борьба с переполненностью тюрем может достигнуть своей цели.

Третий раздел охватывает порядок регулирования «мер, касающиеся досудебной стадии», т.е. снижение количества случаев применения такой уголовно-процессуальной меры пресечения как содержание под стражей.

Четвертый раздел связан с применением «механизма мер судебного разбирательства» и содержит следующие главы: система санкций, вынесение приговора, и роли прокуроров и судей при определении наказания. В разделе определена необходимость пропагандировать вынесение менее суровых приговоров, а также, с целью снизить тяжелую нагрузку на тюремную систему, замена наказания в виде коротких сроков тюремного заключения на иные меры общественного воздействия (принцип № 14). Рекомендацией № R (99) 22 предложено в каждое национальное законодательство внедрить и использовать на практике комбинирование наказания в виде тюремного заключения и иных мер, не связанных с лишением свободы (принцип № 17). При этом, законодатель в обращении к компетентным органам дал пояснения относительно способа добиться снижения уровня использования наказания в виде лишения свободы и расширения применения иных мер общественного воздействия, и т.д. (Принцип № 20).
Последний раздел под названием «Меры, относящиеся к после судебной стадии» посвящен применению наказания и иных мер общественного воздействия в ходе исполнения приговора. В этом случае для того, чтобы достигнуть цели полной замены наказания в виде краткосрочного лишения свободы на иные меры наказания, не связанные с лишением свободы, необходимо обеспечить эффективный общественный мониторинг применения мер наказания; разработать и использовать методы надежного прогнозирования рисков и их оценки, определить дальнейшую стратегию действий с точки зрения риска преступного рецидива и обеспечения общественной защиты и безопасности. Все это должно прибавить уверенности судьям и прокурорам, что альтернатива замены краткосрочного тюремного заключения другим видом наказания будет выглядеть достаточно эффективной мерой (принцип No.22).

\section{3. Дополнение \\ Рекомендации 22 (92) 16 Рекомендацией $\mathbf{R}$ (99)}

Первая часть Рекомендации R (99) 22 , озаглавленная «Основные принципы», содержит принцип 4, имеющий большое значение при решении вопроса о возможности декриминализации отдельных видов преступлений или их переквалификации при вынесении приговоров, связанных с лишением свободы.

На этом принципе, в частности, наиболее точно выстроено содержание Рекомендации (92) 16 Европейских правил альтернативного наказания в 
пользу иных мер, применяемых в обществе. Таким образом, существует обязанность каждого государства - члена СЕ совершенствовать в соответствии с настоящими Правилами свое национальное законодательство в качестве гарантии от риска нарушения основных прав человека при применении этих Правил к лицу, преступившему закон.

Рекомендацией (92) 16 Комитета Министров Совета Европы государствам-членам Европейских правил по применению общественных санкций и мер определены основные принципы и правовая основа применения альтернативных наказаний, гарантии судебной процедуры рассмотрения жалоб, порядок защиты основных прав, согласительная процедура сотрудничества правонарушителя с правоохранительными органами, стандарты действий правоохранительных органов при применении финансового поощрения, роль общественности, условия применения методов в работе, осуществление процессуальных действий и оценка последствий их неприменения.

Правила, благодаря своему содержанию и смыслу, воспринимаются как документ, имеющий большое значение, а именно, содержат перечень санкций и мер по социальной адаптации преступника и порядок применения определенных ограничений его свободы в соответствии с условиями или обязательствами, налагаемыми правоприменительными органами.[3] Таким образом, преступник избегает наказания в виде лишения свободы, но при этом не избегает самого наказания![4]

Меры, применяемые при альтернативных наказаниях, по своей природе являются санкциями, приводящими к ограничениям в виде наложения определенных обязательств, ограничений, ужесточения условий режима, применяемого при альтернативном наказании. То есть, при замене тюремного заключения обусловленным освобождением продолжает существовать угроза нарушения каких-либо гарантированных прав человека.

В каждом конкретном случае остается большой простор для размышлений при выборе способа альтернативного наказания. Ведь целью альтернативного наказания является защита человеческого достоинства, недопущение приобретения преступных наклонностей в условиях изоляции от общества. Поэтому пути поиска иных форм наказания, не связанных с лишением свободы, позволяют избежать деградации личности.

\section{4. Сравнительный обзор и статистика перенаселенности (переполненности) учреждений тюремного типа в связи с увеличением численности заключенных}

Несмотря на текст и смысл положений и принципов, содержащихся в Рекомендации № R (99) 22 и которыми можно было бы руководствоваться, в реальности в некоторых странах зафиксирована тенденция к увеличению численности заключенных в пенитенциарных учреждениях.

Проведенное исследование показало, что в 2010 г. количество заключенных увеличилось до среднего значения числа заключенных 119,6 на 100000 
жителей. По сравнению с 2009 г., когда значение этого числа было 119,4, никаких существенных изменений не произошло. Если рассуждать обобщенно, то в странах с высоким уровнем числа заключенных переполненность тюрем в 2009 году осталась на том же уровне, но с 2010 г. продолжает увеличиваться.

Когда дело доходит до сравнительного обзора стран с высоким уровнем переполненности тюрем необходимо подчеркнуть, что подход в определении этих показателей между странами различен, поскольку различаются инструменты, используемые для рассматриваемого предмета исследования (Совет Европы - ежегодная штрафная статистика: Space 2010). В то же время можно видеть, что плотность числа заключенных в тюремных учреждениях увеличилась (с 96,6\% в 2009 году до 97,5\% в 2010 году). С другой стороны, отмечено, что никаких существенных изменений в ряде государств с числом более 130 заключенных на 100 мест с 2008 года до сегодняшнего дня не произошло. В 2008 году таковых было 6 стран, в 2009 году - 7 стран и в 2010 году - снова 6 стран.

Производя сравнительный обзор европейских стран, можно отметить, что каждая страна решает вопрос переполненности тюрем по-своему. Так, во Франции многочисленные критические замечания направлены в сторону проблемы переполненности тюремных учреждений и нечеловеческих условий содержания, подтверждение которым можно найти в Мезон d'ARRET, учреждении, где до вынесения приговора и направления в соответствующие учреждения находятся подсудимые, a также осужденные на короткие сроки до двух лет.

Компетентные органы уголовноправовой системы Франции выразили озабоченность, в частности, тем, что совместное содержание подсудимых и лиц, отбывающих короткие сроки лишения свободы увеличивает количество случаев рецидива, что в дальнейшем приводит к переизбытку числа заключенных в пенитенциарных учреждениях. По некоторым данным, 68000 задержанных размещены в учреждениях, максимальная заполняемость которых составляет 56100. Подтверждением этой цифры является тот факт, что в 2007 году значительно увеличилось количество приговоренных к минимальным срокам преступников-рецидивистов.[5]

В сегодняшней Бельгии, несмотря на соответствующие международным стандартам условия содержания в пенитенциарных учреждениях, тем не менее, существует проблема переполненности тюрем.[6] Но с другой стороны, изменения в законодательстве, как ожидается, должны снизить негативные последствия от этой проблемы. [7] Однако, на практике встречаются и такие крайности, когда несовершеннолетние правонарушители из-за отсутствия мест в специализированных учреждениях отбывают наказание в том же учреждении наравне со взрослыми правонарушителями.[8]

В России, в связи с изменением подведомственности и передачей полномочий по исполнению уголовных наказаний Министерству юстиции, заметны многочисленные достижения. В соответствии с руководящими прин- 
ципами и рекомендациями, изложенными в международных документах, в основном наблюдаются улучшения условий тюремного содержания. Также отмечено улучшение медицинского обслуживания и обеспечение надлежащих услуг социального характера в отношении сотрудников уголовноисполнительной системы, введение конструктивных программ и мероприятий, в том числе связанных с образованием и профессиональной подготовкой, продуктивным использования времени в закрытых учреждениях, и т.д. [9]

Однако, открытым остается вопрос, вызывающий беспокойство компетентных органов других европейских пенитенциарных систем. Например, в 2001 году Россия столкнулась с ростом числа заключенных, что на $50 \%$ выше, чем в любой другой европейской стране, за исключением Беларуси. Наблюдается также чрезвычайно высокая плотность заключенных, что на $80 \%$ превышает возможности их размещения. Также нарекания поступили в адрес условий содержания в некоторых объектах уголовно-исполнительной системы, отсутствия гигиены и медицинских учреждений, и, конечно, недостаточности финансирования дальнейшего развития пенитенциарных учреждений.[9] Переполненность тюрем и превалирование в общей структуре категорий заключенных категории лиц с недостаточным уровнем развития, безусловно, препятствуют процессу социальной адаптации осужденных, основной целью и задачами которого является дело борьбы с преступностью и другими признаками девиантного поведения.[1] При наличии такой категории заключенных практически невозможно добиться положительных результатов за счет перевоспитания (особенно образования и обеспечения занятости) именно потому, что перевоспитание преступника и подготовка его к жизни в обществе проходит в неестественных и искусственно созданных условиях.

\section{5. Заключительные замечания}

Единственный вывод, который можно сделать из Рекомендации № R (99) 22, содержится в ее вводной части. Комитет Министров подчеркивает необходимость обеспечения мер по борьбе с избыточностью (перенаселенностью) тюремных учреждений и сокращением численности заключенных и это должно стать частью последовательной и рациональной политики борьбы с преступностью, направленной на предотвращение преступления и преступного поведения, эффективное обеспечение законности, общественной безопасности и защиты, индивидуализации наказания и интеграции в социальную среду лиц, совершивших уголовные деяния.

Необходимо разработать и реализовать эффективные программы исправления заключенных во время их пребывания в местах лишения свободы и наблюдения после освобождения из заключения для того, чтобы облегчить процесс вовлечения правонарушителей в социальную среду, снизить уровень рецидива и обеспечить безопасность и защиту общества. Препятствий для этого в принципе нет. 
26 государств-членов Совета Европы, присоединившихся к Европейским тюремным правилам и участвующим в этом процессе, придадут, таким образом, больше уверенности правоприменительным органам в их процессуальной деятельности по уменьшению сроков заключения или при избрании иных альтернативных форм наказания.

\section{Резюме}

Согласно исследованиям и анализу последних статистических данных в отношении заключенных перенаселенность и высокий уровень рецидива являются насущными факторами современной пенитенциарной системы. Альтернативные меры применения наказания выступают непременной категорией в перечне наказаний, предусмотренных законодательством для тех случаев, когда цель наказания может быть достигнута и без лишения свободы. Лишение свободы должно рассматриваться в качестве крайней меры наказания и, следовательно, должно быть предусмотрено только в случае серьезности правонарушения, при котором применение любой другой меры наказания явно недостаточно.

В перечне правоприменительных мер тюремное заключение должно рассматриваться как последняя мера в достижении главной цели наказания. Чтобы уменьшить масштаб тюремной перенаселенности могут быть использованы такие меры, как испытательный срок с проведением контрольных проверок, испытательное приостановление уголовного судопроизводства, общественные работы (работы в интересах общества), судебное заявление, лишение свободы в виде домашнего ареста и т.д.

Переполненность тюрем и рост числа заключенных это серьезная проблема для тюремной администрации и системы уголовного правосудия в целом с точки зрения соблюдения прав человека и норм эффективного управления пенитенциарными учреждениями. Меры по борьбе с переполненностью тюрем и сокращением численности заключенных должны представлять собой последовательную и рациональную политику борьбы с преступностью, направленную на предотвращение преступлений и преступного поведения, эффективное правоприменение, безопасность и защиту общества и т.д.

Наконец, если возникли условия для переполнения мест заключения, особое внимание тюремная администрация должна уделить соблюдению принципа гуманизма по отношению к человеческому достоинству заключенных. С другой стороны, следует расширять применение мер, направленных на снижение фактической длины срока приговора, отдавая предпочтение вышеупомянутым мерам индивидуального наказания.

\section{Библиография:}

1. Arnaudovski Ljupcho CHACHEV Виолета (2000) «заключенные общество». Институт социологических, политических и правовых исследований, Скопье, 2000, С. 23. 
2. Arnaudovski Ljupco Груевски-Drakulevski Александра: 1. «Закон об исполнении наказаний, неотъемлемой текста предисловия, краткими пояснениями терминов и Регистрация с вложениями.» Studiorum, Скопье, 2011, С. 208, 2. «пенология-первая часть». Факультет «Юстиниан I»-Скопье, 2013., 3.

3. Kambovski Владо. Уголовное право - Общая часть. Культура, Скопье, 2004, C. 938 .

4. Buzarovska-Lazhetikj Гордана. «Альтернативы тюремному заключению». Студент слово, Скопье, 2003, С. 228.

5. Akinbola Патрисия, Farjood Надя: тюремная реформа - Решение проблемы переполненности тюрем французских, 2011 (доступ: февраль 2014 г.), по адресу: http://www.humanityinaction.org/knowledgebase/368-prison-reformaddressing-overcrowding-in-french-prisons.

6. Кан Мэтью: бельгийские заключенные сделать время за границей, освободив переполненности дома 05 февраля 2010 (доступ: февраль 2014 г.), по адресу: http://www.dw.de/belgian-prisoners-do-time-abroad-relieving-overcrowding-athome/a-5221011.

7. Дамс, Том «, которые поддерживаются жертвы? Переполненность тюрем и реформы пенитенциарной системы в Бельгии «. Международный журнал права, преступности и правосудия № 36, 2008, С.153-167.

8. Кан Мэтью: бельгийские заключенные сделать время за границей, освободив переполненности дома 05 февраля 2010 (доступ: февраль 2014 г.), по адресу: http://www.dw.de/belgian-prisoners-do-time-abroad-relieving-overcrowding-athome/a-5221011.

9. Волмсли, Рой «Дальнейшее развитие в пенитенциарных системах Центральной и Восточной Европы, достижения, проблемы и задачи». Публикация серии № 41, Хельсинки, 2003, С.457.

\section{References (transliterated):}

1. Arnaudovski Ljupcho CHACHEV Violeta (2000) "zaklyuchennye obshchestvo". Institut sotsiologicheskikh, politicheskikh i pravovykh issledovanii, Skop'e, 2000 , S. 23.

2. Arnaudovski Ljupco Gruevski-Drakulevski Aleksandra: 1. «Zakon ob ispolnenii nakazanii, neot' 'emlemoi teksta predisloviya, kratkimi poyasneniyami terminov i Registratsiya s vlozheniyami.» Studiorum, Skop'e, 2011, S. 208, 2. "penologiyapervaya chast"”. Fakul'tet "Yustinian I" - Skop'e, 2013., 3.

3. Kambovski Vlado. Ugolovnoe parvo - Obshchaya chast'. Kul'tura, Skop'e, 2004, S. 938.

4. Buzarovska-Lazhetikj Gordana. “Al’ternativy tyuremnomu zaklyucheniyu”. Student slovo, Skop'e, 2003, S. 228. 
5. Akinbola Patrisiya, Farjood Nadya: tyuremnaya reforma - Reshenie problemy perepolnennosti tyurem frantsuzskikh, 2011 (dostup: fevral' 2014 g.), po adresu: http://www.humanityinaction.org/knowledgebase/368-prison-reform-addressingovercrowding-in-french-prisons.

6. Kan Met'yu: bel'giiskie zaklyuchennye sdelat' vremya za granitsei, osvobodiv perepolnennosti doma 05 fevralya 2010 (dostup: fevral' 2014 g.), po adresu: http://www.dw.de/belgian-prisoners-do-time-abroad-relieving-overcrowding-athome/a-5221011.

7. Dams, Tom “, kotorye podderzhivayutsya zhertvy? Perepolnennost' tyurem i reformy penitentsiarnoi sistemy v Bel'gii “. Mezhdunarodnyi zhurnal prava, prestupnosti i pravosudiya № 36, 2008, S.153-167.

8. Kan Met'yu: bel'giiskie zaklyuchennye sdelat' vremya za granitsei, osvobodiv perepolnennosti doma 05 fevralya 2010 (dostup: fevral' 2014 g.), po adresu: http://www.dw.de/belgian-prisoners-do-time-abroad-relieving-overcrowding-athome/a-5221011.

9. Volmsli, Roi “Dal'neishee razvitie v penitentsiarnykh sistemakh Tsentral'noi i Vostochnoi Evropy, dostizheniya, problemy i zadachi”. Publikatsiya serii № 41, Khel'sinki, 2003, S.457. 